\title{
The Epidemiology Study in Multiple Sclerosis - Relevance to Natural History
}

\author{
Jeffrey Scott Sloka, MD, PhD*
}

\begin{abstract}
Multiple sclerosis (MS) is a chronic, demyelinating disease of the central nervous system white matter that has been extensively studied using the epidemiological approach, and yet an etiology for the disease remains elusive. This paper presents a review of past publications that have made suggestions toward the design of epidemiological studies in MS. A formal search strategy is described, and a short summary of these papers is provided. A natural history of MS based on previous studies is proposed as a framework for describing future directions in the neuroepidemiology of the disease, and categorization based on the clinical forms of MS is described. Within the context of a proposed natural history, suggestions are made on the use of sub-regionalization in cluster studies across different domains, as well as on the use of specific reference points in a patient's lifetime in the analysis of clusters.
\end{abstract}

\section{INTRODUCTION}

Multiple sclerosis (MS) is a chronic, demyelinating disease of the central nervous system white matter that may cause paralysis, sensory disturbances, incoordination, visual impairment, and alterations in bowel, bladder, and sexual function(1). The precise etiology of MS has not been elucidated; however, many observations have been made that suggest both genetic susceptibility and environmental factors play a role(2). In the search for an environmental contribution to the etiology of MS, numerous epidemiological studies have been conducted, and a large body of literature based on the results of these studies has been published $(1,3)$. Many hypotheses of exogenous causes of MS have been explored (4), including exposure to viruses $(5,6)$, organic solvents (7), diet (8), and soil type (9). Intriguingly, many purported associations remain controversial, and studies have shown conflicting results on the contribution of viral causes to etiology (1), conflicting

*To whom correspondence should be addressed: 108 Moss Heather Drive, St. John's, Newfoundland, Canada A1B 4S1; Email: p97jss@mun.ca genetic susceptibilities in similar populations to different categories of MS $(10,11)$, evidence that the pathology may not follow clinical observations $(12,13)$, and large temporal gradients in disease populations (either related to changes in environmental factors or to diagnostic coverage) $(14,15)$. Consistent study design in future comparative studies may help to explain these differences and add to the significance of previous research.

The role of the epidemiological study in the search for etiology is well-documented16. In fact, much of the evidence for both genetic susceptibility and environmental triggers in MS has been elucidated from epidemiological studies $(1,2)$. Historically, variations in incidence and prevalence have been related to temporal and geographical gradients and other variations in risk, in order to generate hypotheses towards the causation of disease. The epidemiological approach has not yielded all the answers, but it holds great merit and much potential to further contribute to the knowledge of disease etiology (16). Although many epidemiological studies have been published, few recent papers have been dedicated to suggesting study methodologies in order to elucidate new epidemiological information, especially in the context of a natural history (16-27). 


\section{Background}

An epidemiological study of MS in Newfoundland is currently being conducted in order to both update the results of a previous study (28) and to explore further hypotheses toward the etiology of MS. A survey of previous epidemiological studies was conducted using MEDLINE in order to gain insight from other authors' past experiences. Search terms used were the following: multiple sclerosis and (epidemiology or epidemiological). Altogether, 1791 citations were found for all available years and a review through the abstracts and titles from 1990 to 2001 yielded references that were used to discover the recent trends and suggestions for the design and administration of epidemiological studies for MS (16-27). Although older studies were indeed reviewed, only references to recent papers were included in this summary since an understanding of recent trends in the neuroepidemiology of MS was sought. Furthermore, the historical context of older reviews was captured in the newer reviews. Several recent papers that presented results of epidemiological studies were also surveyed for methodology, data analysis, and concluding suggestions towards the design of both their study and studies conducted by others $(27,29-38)$. Papers that discussed the epidemiology of MS in the context of the natural history of the disease were particularly sought, but none was found that presented suggestions in the context of a formally presented natural history.

To summarize the existing suggestions of others, new epidemiological insights into MS beget new directions for the study of MS. Problems of current study design do exist but can be overcome. For example, very little of a patient's residential history is captured on consultation sheets, and so other means of information gathering are required (such as questionnaires), and their respective limitations must be accepted (such as response rate). However, it is possible to gather such information using questionnaires (29), and methodologies for optimizing the amount of information that one can elicit from a questionnaire have been suggested by others (21), so lack of patient information should not be a limiting factor. As well, methods to correct for known deficits in data have been proposed $(19,37)$, as have suggestions on the logistics of conducting a study (36). Papers have suggested that age, gender, and race should be collected while performing epidemiological studies and adjustments for these variables made (18); methods to minimize bias while performing ecological studies have also been made18. Others have discussed methods of eliciting information from time and space analyses $(20,22,39)$ and still others have discussed epidemiological methodologies in the context of genetic research $(20,38)$.
Since the design of epidemiological studies in MS has not been suggested in the context of a proposed natural history for the disease, this paper first presents such a proposal and then makes suggestions towards future study designs. First, a general discussion on latency and induction periods is presented as an introduction to the concepts of formalizing a natural history. The section that follows describes results of several observational studies on MS pertaining to genetic susceptibility, environmental contributions, and disease heterogeneity. The final section formally ties the observations of these studies together and makes suggestions towards future directions in cluster analysis as related to natural history.

\section{NATURAL HISTORY}

Current theories on the natural history of a disease have implications on the design of epidemiological studies. In fact, the natural history of a disease may shape the type of data that can be drawn from a study. For example, the time course of the disease affects the feasibility of a study in diseases with sub-clinical periods. Diseases with either long time courses or long latency periods between exposure and disease are both more expensive to study and more susceptible to loss from follow-up. Importantly, however, knowledge of the current thinking on the natural history of a disease also guides one to develop hypotheses in order to supplement or refute current theories.

The concepts of latency and induction period are related to the sub-clinical and clinical progression of MS and are important in the early stages of the disease. Therefore, observations made at these stages contribute to knowledge of the etiology of MS.

\section{Induction Period and Latency}

The induction period is defined as the period of time from causation until disease initiation40 (Figure 1). The beginning of the induction period is the time at which the earliest component cause influences the etiologic mechanism (40). In the case of a genetic susceptibility, the induction period begins at conception. In people who are genetically predisposed to a disease that is environmentally triggered (possibly type I diabetes, MS, atherosclerotic heart disease), the concept of an environmentally-specific induction period may be defined as the period from the first environmental exposure until disease initiation (Figure $1)$.

It is possible to have multiple dependent or independent environmental exposures (41). These can either be the same environmental pathogen or different pathogens altogether. Initial environmental exposures precede a final exposure that concludes the disease 


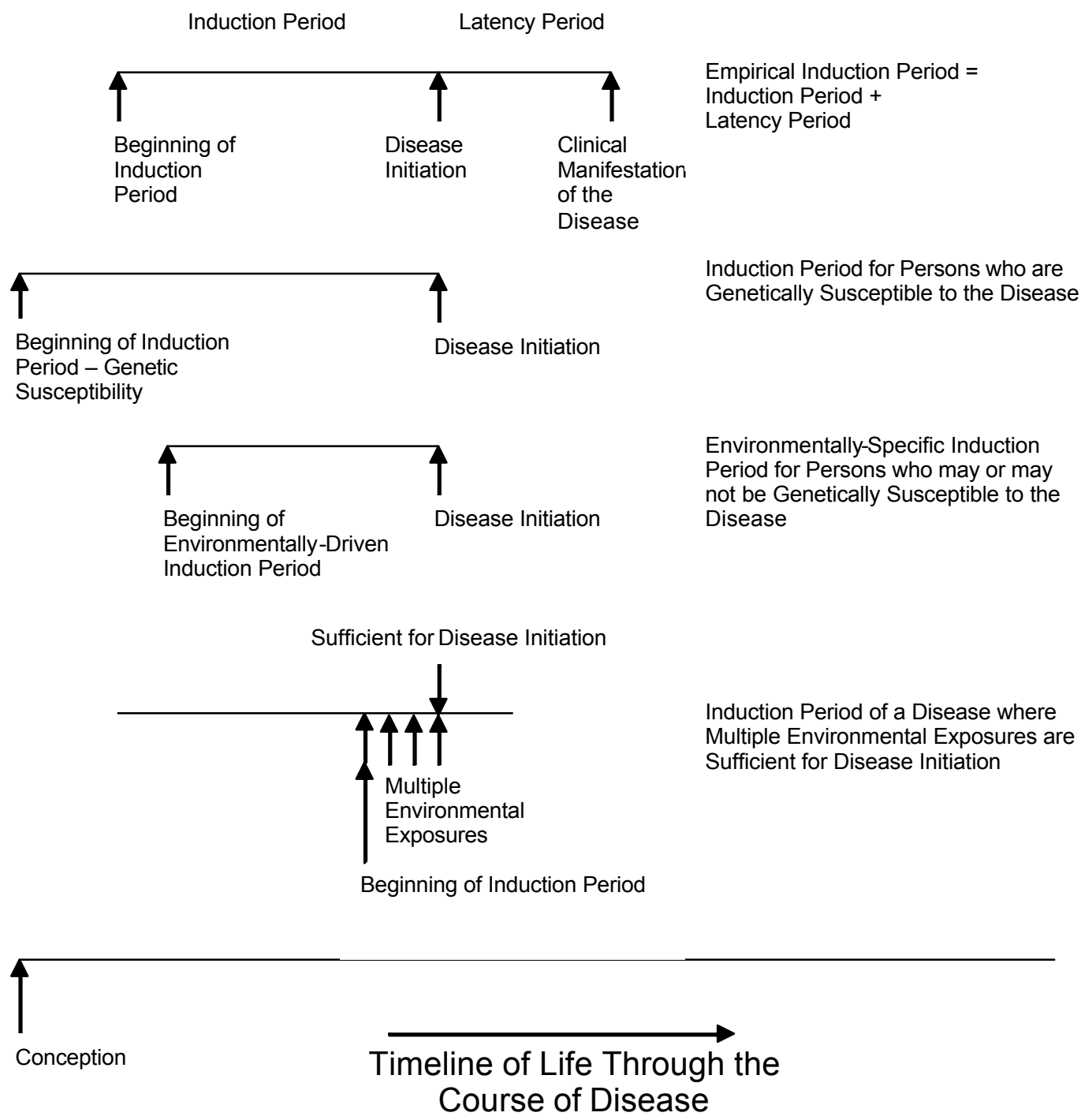

Figure 1. Definition of Latency Period, Induction Period, Empirical Induction Period and Environmentally-Specific Induction Period

initiation process - the final exposure (genetic mutation or environmental exposure) is sufficient to initiate the disease process (Figure 1).

The disease may clinically manifest itself immediately after the final environmental exposure (e.g. bacterial toxins leading to gastrointestinal disease), or it may take decades to manifest itself (e.g. diethylstilbesterol exposure in utero leading to vaginal cancer), depending on the natural history of the disease. This time interval between the initiation of disease and the time at which the disease is first detected, either by the individual or clinician, is called the latency period40. In other words, this latency period is the time during which the disease is initiated but "hidden" and is typified by diseases such as type I diabetes and MS. In practice, it is sometimes difficult to separate the induction period and the latency period, and so the sum of these two periods is generally used and is defined as the empirical induction period (EIP) (40) (Figure 1).

Therefore, the epidemiological contribution to quantifying the early stages of the natural history of a disease may include the following: the elucidation of the precise pathogen(s), the discovery of the number of exposures required for sufficient cause, the induction period length, the latency period length, and the effects of differing genetic susceptibilities on all of these variables.

\section{GENETIC AND ENVIRONMENTAL CONTRIBUTIONS}

As was previously stated, both environmental factors and genetic susceptibility are felt to contribute to disease induction $(1,2)$. This section presents the results 
of epidemiological studies specific to both the genetic and environmental contribution to disease. Additionally, disease heterogeneity is discussed since different clinical categories of MS have different clinical presentations and pathologies $(12,13)$ with different natural histories.

\section{Genetic Contribution}

Concordance rates among monozygotic twins with MS is approximately $31-40 \%$ whereas the concordance rates among fraternal twins and non-twin siblings is approximately $3-5 \%(42,43)$ - this demonstrates an approximate six to eight times increase in relative risk. As well, prevalence rates among non-biological siblings adopted into a family are similar to prevalence rates of MS found in the general population and significantly less than for biological relatives, suggesting a significant genetic component to the familial aggregation of MS (42). Genetic susceptibility has also been shown to vary with several genetic markers (4447 ), especially the human leukocyte antigen (HLA)DR2 antigen on chromosome 6 (44).

The mode of transmission is complex and sporadic in most cases (2). The susceptibility itself and the timing of disease initiation may depend on the particular combination of disease susceptibility markers in the individual, thus having an effect on the length of the EIP. As well, the beginning of the EIP may be as early as conception for those with a genetic predisposition (Figure 1). Therefore, a variation in the EIP should be accounted for in any model of the natural history of diseases with a continuum of multiple susceptibility markers. In populations with longer EIPs, there is a greater risk of confounding factors such as migration and co-morbidity that complicate study results. Longer EIPs also increase the chance that the empirical induction period has a greater variability (40). Therefore, the genetic makeup of the population under study should be accounted for in any model of natural history.

\section{Environmental Contribution}

A geographical distribution highlighting increased MS prevalence with higher latitudes provides evidence of an environmental contribution (48). However counter to this correlation with latitude, large variations in prevalence among geographically close regions with similar latitudes have been noted in places such as Sicily and Malta $(49,50)$. This may suggest that locallyspecific etiologies (either environmental or genetic) contribute to disease pathogenesis.

Migrant studies also contribute to proof of an environmental component. The results of multiple migrant studies in MS (51-57) suggest that people who migrate before adolescence acquire the incidence rates of the region to which they have migrated. In contrast, people that migrate to a region after adolescence retain the incidence rate of the region from which they grew up (58). This compelling evidence is fairly consistent for migration from areas of high risk to areas of low risk and suggests that there is a part of the disease process that depends on geographical location, possibly involving an environmental pathogen. However, the evidence is also fairly consistent that migration from areas of low risk to areas of high risk is not associated with a substantial change in risk (58). This diminishes the strength of conclusions that can be drawn from all migrant studies but does permit the observation that both geography and age play some as-yet undetermined role in the natural history of the disease.

Studies of the age at which people migrate have shown that a general age range might be important in the natural history of the disease in terms of susceptibility to an environmental pathogen. Many studies on age-at-migration suggest that either a general age range (51-57) or a "critical age" at migration alters the risk of disease, and this critical age tends to be close to $15(52-54,57)$ (e.g. populations migrating before the age of 15 from high to low risk regions acquire the lower risk of susceptibility). The implication of these studies is that the risk of acquiring MS may be largely determined by the age of 15 years. However, these studies are based on very small population sizes (58). In other studies from Australia (59) and the US (56), a relation between the age of migration and the change in risk of acquiring MS has been suggested, and still others have suggested that the critical age is not 15 but exists sometime within the latter part of the first two decades of life $(57,58)$.

One study that stands out is an analysis of MS incidence data from an "outbreak" of MS on the Faroe Islands related to the stationing of British troops there during World War II (41). The author analyzed the data and considered both an age at exposure and a latency period of the disease. A model was developed using a critical age of puberty for a sufficient cause exposure (13 years old for females and 14 years old for males), and an average latency period could be consistently estimated from this age to be 5 years for females and 6.3 years for males until the manifestation of disease symptoms. The biological plausibility of these results is supported by the physiological changes occurring at puberty, with the idea that some unknown factor that changes the susceptibility occurs at that point in life and may be either hormonal or developmental in nature. The observations in this study have problems of low power. However, others have calculated latency periods and found ranges of 9 years (60), 9-12 years (61), and 8- 
Table 1. Epidemiological characteristics of different clinical forms of MS. There is a large variation in reported values. Therefore, ranges are given where possible and significant comparisons within single studies were used. These differences in epidemiological characteristics suggest that different natural histories should be considered for each clinical form. PPMS tends to have a later age of onset and a smaller male-to-female ratio

\begin{tabular}{|c|c|c|c|c|}
\hline Clinical Classification & Clinical Course & Age of Onset (years) & Male to Female Ratio & Percentage of MS Patients \\
\hline $\begin{array}{c}\text { Relapsing Remitting MS } \\
\text { (RRMS) }\end{array}$ & $\begin{array}{c}\text { MS with acute } \\
\text { exacerbations and full or } \\
\text { nearly full remission to } \\
\text { baseline }\end{array}$ & $\begin{array}{c}29.2(66) \\
30.7+/-8.4(67)\end{array}$ & $\begin{array}{c}\text { Not a universal } \\
\text { difference with PPMS } \\
(68)\end{array}$ \\
\hline $\begin{array}{c}\text { Secondary Progressive } \\
\text { MS (SPMS) }\end{array}$ & $\begin{array}{c}\text { MS that was initially } \\
\text { RRMS but now retains } \\
\text { progressively additive } \\
\text { deficits with each } \\
\text { exacerbation }\end{array}$ & $\begin{array}{c}50 \% \text { of RRMS after } 10 \\
\text { yrs, 90\% after } 25 \text { yrs } \\
(69)\end{array}$ & $1: 3.2(67)$ \\
\hline $\begin{array}{c}\text { Primary Progressive MS } \\
\text { (PPMS) }\end{array}$ & $\begin{array}{c}\text { Mrogressive course from } \\
\text { onset }\end{array}$ & $35.9+/-9.9(67)$ & $1: 1.7(67)$ \\
\hline
\end{tabular}

14 years (60), and these results are compelling enough to consider the concept of a critical age and latency period. Yet difficulties comparing the data of migration studies arise due to the lack of uniform diagnostic criteria, uncertainty about the latency period, deficiencies in case finding and follow-up, and enormous variability in the clinical presentation and course of the disease (19).

\section{Heterogeneity of Disease}

To further complicate matters epidemiologically, MS may in fact be a collection of heterogeneous disorders by epidemiological, pathological, and diagnostic parameters and may therefore be a spectrum of disease instead of one disease entity $(62,63)$. Based on an international survey of MS experts, MS has been clinically classified as relapsing-remitting (RRMS), secondary progressive (SPMS), and primary progressive (PPMS) disease (see Table 1 for a description of clinical course and characteristics)64. This survey was based on observations of the clinical presentation and course of MS. Another category, progressive remitting (PRMS), was included in the survey paper; however others have suggested that PRMS is, in fact, a variant of PPMS (65).

Differences in the epidemiological characteristics of disease categories suggest that each clinical form has a separable natural history. Further clinical, diagnostic, and immunological evidence for categorizing PPMS as a separate entity from RRMS and SPMS includes lack of clinical attacks (70), fewer lesions on MRI (70), higher in vitro migration (73), different epidemiology (62), differences in immune cell products (73), less inflammation on necroscopy70, and differences in HLA prevalences (74-76). Additionally, it has been reported that SPMS, although an apparent continuation from RRMS, has significant differences from RRMS and
PPMS including differences on diagnostic imaging (77).

Given that genetic, pathologic, and clinical differences exist among RRMS, SPMS, and PPMS, one might be tempted to categorize MS based on these distinctions. However, new evidence suggests that the spectrum of disease may also be delineated along pathophysiological boundaries, and these newlyconsidered boundaries may or may not correlate with the clinical/genetic boundaries suggested above (63). Observations suggest that one form of MS may be characterized by inflammation directed against myelin while another form of MS may be due to progressive axonal degeneration $(12,78)$. Whether the pathophysiological categorization of MS correlates with the clinical/genetic categorization of MS remains to be established. However, the clinical categorization of MS should at least be considered during the design of epidemiological studies since each clinical entity appears to have a different natural history as exemplified by differences in age of onset, male-tofemale ratio, and the difference in likelihood of presenting after age 40 (67).

\section{A PROPOSED NATURAL HISTORY}

A proposed natural history (Figure 2) would begin with genetic factors that contribute to an individual's susceptibility from conception. As described above, multiple genetic factors contribute to susceptibility, and different combinations of these factors within individuals may affect the length of the induction period, the number of environmental exposures required for sufficient cause, and the clinical progression of disease.

The environmental contribution to disease initiation may occur either in utero or after birth. This contribution may include different factors (such as 

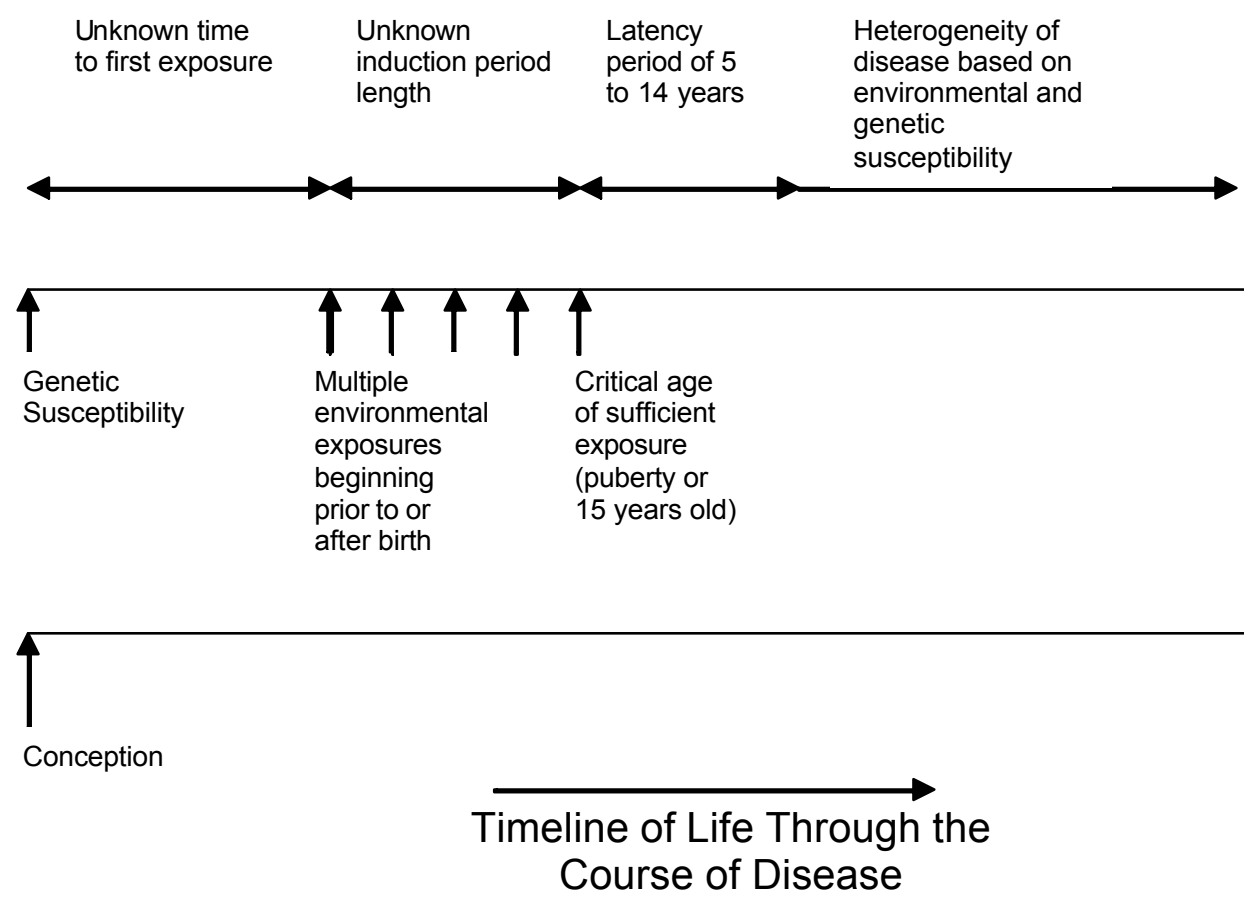

Figure 2. A proposed natural history for MS including genetic factors that affect an individual's susceptibility from birth, multiple environmental exposures, a critical age of sufficient exposure, unknown induction period length, an estimated latency period, and a heterogeneous disease presentation.

exposure to viruses $(5,6))$, and multiple exposures may be necessary, again depending on the genetic susceptibility of the individual. Therefore, both genetic and environmental variability contributes to a highly variable EIP.

An individual may have different susceptibility to disease initiation depending on a critical age of susceptibility or their pubertal status (as highlighted above in the migration studies). Following this critical age, (highly variable) latency periods have been estimated (see environmental contributions above).

Finally, different clinical categories of MS have been described, each with a different clinical course. There are different ages of onset, different rates of progression, and different male-to-female ratios among the categories, highlighting different natural histories for each.

\section{SUGGESTIONS FOR FUTURE EPIDEMIOLOGICAL STUDIES}

Now that a framework for the natural history of MS has been proposed, proposals on the epidemiological search for an etiology may be made in the context of this framework. A body of evidence suggests that clusters of MS exist in both space and time (79-84). In searching for clusters of disease in time and space, which may in turn lead researchers to possible environmental or genetic contributions to disease induction, a study of a large geographical region may be regionalized for the comparison of subregions. The subregionalization is normally selected to reflect differences in subregions in some respect (soil type, type of industry). These subregions need to be large enough to guarantee sufficient statistical power for their comparison (85). It is preferable to have a migrationally stable population for cluster studies so that exposures in space can be correlated without inter-subregional travel diluting the conclusions that can be drawn on exposure versus effect.

Methods to "re-assign" the incidences and/or prevalences have been suggested by several authors $(19,86)$. Figure 3 shows two representations of four geographical subregions. The diagram on the left depicts a hypothetical prevalence map with a uniformly constant prevalence across all subregions. In this example, the prevalence is assigned to the subregion of residence at the time of diagnosis. For the representation at the right, the prevalence is recalculated for an assignment of residence at the time of first attack (which may be different than the residence at the time of diagnosis) indicating, in this hypothetical representation, that a person living in the upper left subregion at the time of diagnosis actually had their first attack while residing in the lower right subregion. If a sufficient number of people had attacks in a given subregion that is significantly more than in other 
regions, a cluster in that region would be found and further searching would be necessary to elicit a cause. Incidence remapping is also applied in this fashion.

Thus, time and space clusters may be "hidden" within data sets and may be elucidated by giving a new time reference point for the incidence and/or prevalence, given that these reassignments correlate with biologically plausible periods in the natural history of the disease. This type of reassignment can distill spacetime clusters that would not be possible if the natural history of the disease had not been considered.

It is possible to reassign prevalences and/or incidences to dates of first attack if dates and locations of residency are known. It is also possible to reassign prevalences and/or incidences to increments of years prior to first attack, with the age of first attack being the reference. This reassignment process is designed to "simulate", or readjust to, a series of hypothetical latency and/or induction periods of differing length. Problems with this new reassignment method include a dilution of effect across time (a dilution of effect can

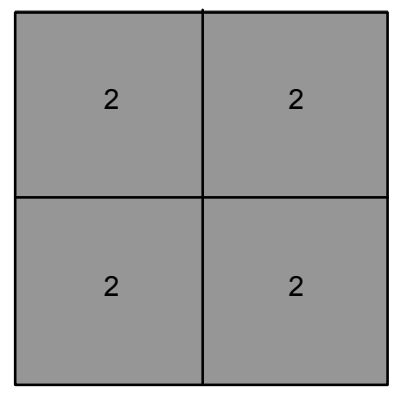

Incidence assigned for residence at time of diagnosis

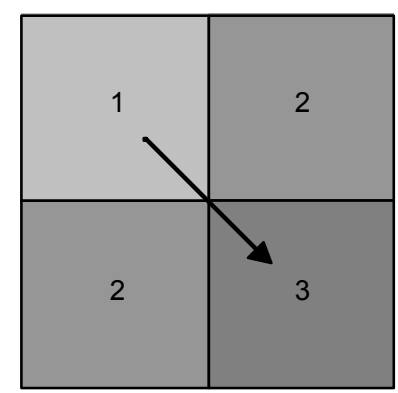

Incidence assigned for residence at time of first attack

Figure 3. Hypothetical incidence maps showing reassignment of incidences based on subregion of residence at first attack occur in a case-control study between two groups if the latency period is not chosen correctly (40)).

Reassignment can also be based on an estimated critical age for susceptibility, such as a fixed age (e.g. 15 years old) or the individual's age at puberty. If the natural history of a disease includes a time period where a sufficiently long latency period exists, an estimated latency period preceding the critical age can also be used to look for clustering. This again necessitates commenting on the residential stability of the population under study. If a population is largely stable from the time of birth to the critical age, then a consistent exposure history might be hypothesized. If, however, the population is more transient, then any conclusions based on exposure are considerably weakened.

Finally, reassignment can be referred to the time of birth or subsequent years thereafter. There is some evidence to support the relation of MS to the acquisition of measles (87), a childhood illness that generally occurs prior to most of the "critical age" estimates. A possible reassignment time might be the mean age for the contraction of measles. The time of birth can also be used as the reference time for incidence/prevalence reassignment because this represents a significant change in the environment of the human, and subsequent exposure to new environmental pathogens.

In terms of designing a cluster analysis study, important dates should be captured for reassignment of "attacks." Ideally, the exact locations of habitation from birth until the first attack would be captured for each patient. This would give invaluable information for the purposes of comparisons between regions. For the purpose of incidences, date and place of residence of first attack instead of date of diagnosis is more physiologically useful. Date and place of residence for (i) puberty, (ii) an estimated latency period before puberty, (iii) an estimated latency period before first attack, (iv) at birth, and (v) a mean time to exposure of viral illnesses after birth are all equally relevant depending on the intent of the study.

In order to search for an etiology for this complex and enigmatic disease, a migrationally stable and sufficiently large population with very little interregional travel is desired in order to strengthen conclusions about exposure/disease occurrence. A population with access to a sufficient number of neurologists and medical facilities (MRI, facilities to test for oligoclonal banding) is also required so that regional differences can be stated to be due to variations in exposure/genetics and not due to lack of health care access. Uniform diagnostic criteria are essential and since MS is purported to be a heterogeneous disease, diagnoses should also capture the specific type of MS 
because relapsing-remitting MS can have different epidemiological characteristics than primary progressive MS.

Additionally, regions do not have to be geographical regions per se. Regionalization in a cluster analysis is usually geographical, but could also be done virtually with other categorizations. An example would be water supply source. Towns in the same region could have chlorinated water, be on boil order, have fluorination, etc. These categories could be the "subregions" and time and space clusters could be analyzed in the "water domain" rather than the "geographical domain."

\section{CONCLUSIONS}

The natural history of a disease guides the design of epidemiological studies of that disease. This paper has presented suggestions for study design in the context of a formally described natural history for MS. Specifically, studies should analyze disease prevalence and incidence based on the type of MS. Studies may analyze subregions based on geography, but also may subregionalize based on virtual domains not tied to geography. Ideally, one should study homogeneous populations that are migrationally stable. Reference points within an individual's lifetime (i.e. time/place of first attack, time/place of birth, time/place of puberty) may be equally important in determining clusters. Studies should look for "critical ages" based on these reference points. Most importantly, one should account for any of these possibilities early in the design of the study so one may maximize the information that can be analyzed from the data. If the design of the cluster study is flexible enough, the search for an ecological etiology can be sought from any clusters that are found.

\section{ACKNOWLEDGEMENTS}

The author would like to acknowledge the support and inspiration of the spirit of clinical MS research in Newfoundland, Dr. William Pryse-Phillips.

\section{REFERENCES}

1 Paty DW, Ebers GC. Multiple Sclerosis. Contemporary Neurology Series 1998; 50:Chapter 4 - Diagnosis.

2 Noseworthy JH, Lucchinetti C, Rodriguez M, Weinshenker BG. Multiple sclerosis. N Engl J Med 2000; 343(13):938-952.

3 Wolfson MC. Health-adjusted life expectancy. Health Rep 1996; 8(1):41-46.

4 Lauer K. Ecologic studies of multiple sclerosis. Neurology 1997; 49(2 Suppl 2):S18-S26.

5 Hodge MJ, Wolfson C. Canine distemper virus and multiple sclerosis. Neurology 1997; 49(2 Suppl 2):S62-S69.

6 Hernan MA, Zhang SM, Lipworth L, Olek MJ, Ascherio A Multiple sclerosis and age at infection with common viruses. Epidemiology 2001; 12(3):301-306.

7 Landtblom AM. Exposure to organic solvents and multiple sclerosis. Neurology 1997; 49(2 Suppl 2):S70-S74.

8 Lauer K. Diet and multiple sclerosis. Neurology 1997; 49(2
Suppl 2):S55-S61.

9 Irvine DG, Schiefer HB, Hader WJ. Geotoxicology of multiple sclerosis: the Henribourg, Saskatchewan, cluster focus. II. The soil. Sci Total Environ 1988; 77(2-3):175-188.

10 Fukazawa T, Yamasaki K, Ito H, Kikuchi S, Minohara M, Horiuchi I et al. Both the HLA-CPB1 and -DRB1 alleles correlate with risk for multiple sclerosis in Japanese: clinical phenotypes and gender as important factors. Tissue Antigens 2000; 55(3):199-205.

11 Marrosu MG, Murru MR, Costa G, Murru R, Muntoni F, Cucca F. DRB1-DQA1-DQB1 loci and multiple sclerosis predisposition in the Sardinian population. Hum Mol Genet 1998; 7(8):1235-1237.

12 Lucchinetti C, Bruck W, Noseworthy J. Multiple sclerosis: recent developments in neuropathology, pathogenesis, magnetic resonance imaging studies and treatment. Curr Opin Neurol 2001; 14(3):259-269.

13 Lucchinetti CF, Rodriguez M. The controversy surrounding the pathogenesis of the multiple sclerosis lesion. Mayo Clin Proc 1997; 72(7):665-678.

14 McCall MG, Brereton TL, Dawson A, Millingen K, Sutherland JM, Acheson ED. Frequency of multiple sclerosis in three Australian cities--Perth, Newcastle, and Hobart. J Neurol Neurosurg Psychiatry 1968; 31(1):1-9.

15 Hammond SR, McLeod JG, Millingen KS, Stewart-Wynne EG, English D, Holland JT et al. The epidemiology of multiple sclerosis in three Australian cities: Perth, Newcastle and Hobart. Brain 1988; 111 ( Pt 1):1-25.

16 Compston A. The epidemiology of multiple sclerosis: principles, achievements, and recommendations. Ann Neurol 1994; 36 Suppl 2:S211-S217.

17 Hibberd PL. Use and misuse of statistics for epidemiological studies of multiple sclerosis. Ann Neurol 1994; 36 Suppl 2:S218-S230

18 Lauer K. Ecologic studies of multiple sclerosis. Neurology 1997; 49(2 Suppl 2):S18-S26.

19 Poser CM, Benedikz J, Hibberd PL. The epidemiology of multiple sclerosis: the Iceland model. Onset- adjusted prevalence rate and other methodological considerations. J Neurol Sci 1992; 111(2):143-152.

20 Compston A. The epidemiology of multiple sclerosis: principles, achievements, and recommendations. Ann Neurol 1994; 36 Suppl 2:S211-S217.

21 Boiko A. Data collection guidelines for questionnaires to be used in case- control studies of multiple sclerosis. Neurology 1997; 49(2 Suppl 2):S75-S80.

22 Kurtzke JF. Epidemiology of multiple sclerosis. Does this really point toward an etiology? Lectio Doctoralis. Neurol Sci 2000; 21(6):383-403.

23 Compston A. Genetic epidemiology of multiple sclerosis. J Neurol Neurosurg Psychiatry 1997; 62(6):553-561.

24 Cowan LD, Leviton A, Dammann O. New research directions in neuroepidemiology. Epidemiol Rev 2000; 22(1):18-23.

25 Granieri E, Casetta I, Tola MR. A multicenter study methodologic experience from a multicenter case- control study in Italy. The Italian Multiple Sclerosis Study Group. Neurology 1997; 49(2 Suppl 2):S33-S41.

26 Lauer K. Environmental associations with the risk of multiple sclerosis: the contribution of ecological studies. Acta Neurol Scand Suppl 1995; 161:77-88.

27 Weinshenker BG. Epidemiologic strategies to detect an exogenous cause of MS. Acta Neurol Scand Suppl 1995; 161:93-99.

28 Pryse-Phillips WE. The incidence and prevalence of multiple sclerosis in Newfoundland and Labrador, 1960-1984. Ann Neurol 1986; 20(3):323-328. 
29 Broadley SA, Deans J, Sawcer SJ, Clayton D, Compston DA. Autoimmune disease in first-degree relatives of patients with multiple sclerosis. A UK survey. Brain 2000; 123 ( Pt 6):11021111.

30 Hader WJ, Elliot M, Ebers GC. Epidemiology of multiple sclerosis in London and Middlesex County, Ontario, Canada. Neurology 1988; 38(4):617-621.

31 Warren S, Warren KG. Prevalence, incidence, and characteristics of multiple sclerosis in Westlock County, Alberta, Canada. Neurology 1993; 43(9):1760-1763.

32 Warren S, Warren KG. Prevalence of multiple sclerosis in Barrhead County, Alberta, Canada. Can J Neurol Sci 1992; 19(1):72-75.

33 Klein GM, Rose MS, Seland TP. A prevalence study of multiple sclerosis in the Crowsnest Pass region of southern Alberta. Can J Neurol Sci 1994; 21(3):262-265.

34 Sweeney VP, Sadovnick AD, Brandejs V. Prevalence of multiple sclerosis in British Columbia. Can J Neurol Sci 1986; 13(1):4751.

35 Ghadirian P, Jain M, Ducic S, Shatenstein B, Morisset R. Nutritional factors in the aetiology of multiple sclerosis: a casecontrol study in Montreal, Canada. Int J Epidemiol 1998; 27(5):845-852.

36 Granieri E, Casetta I, Tola MR. A multicenter study methodologic experience from a multicenter case- control study in Italy. The Italian Multiple Sclerosis Study Group. Neurology 1997; 49(2 Suppl 2):S33-S41.

37 Esbjerg S, Keiding N, Koch-Henriksen N. Reporting delay and corrected incidence of multiple sclerosis. Stat Med 1999; 18(13):1691-1706.

38 Cooper GS, Miller FW, Pandey JP. The role of genetic factors in autoimmune disease: implications for environmental research. Environ Health Perspect 1999; 107 Suppl 5:693-700.

39 Weinshenker BG. Epidemiologic strategies to detect an exogenous cause of MS. Acta Neurol Scand Suppl 1995; 161:93-99.

40 Rothman KJ. Induction and latent periods. Am J Epidemiol 1981; 114(2):253-259.

41 Fischman HR. Multiple sclerosis: a two-stage process? Am J Epidemiol 1981; 114(2):244-252.

42 Ebers GC, Sadovnick AD, Risch NJ. A genetic basis for familial aggregation in multiple sclerosis. Canadian Collaborative Study Group. Nature 1995; 377(6545):150-151.

43 Sadovnick AD, Armstrong H, Rice GP, Bulman D, Hashimoto L, Paty DW et al. A population-based study of multiple sclerosis in twins: update. Ann Neurol 1993; 33(3):281-285.

44 Jersild C, Fog T, Hansen GS, Thomsen M, Svejgaard A, Dupont B. Histocompatibility determinants in multiple sclerosis, with special reference to clinical course. Lancet 1973; 2(7840):12211225.

45 Schrijver HM, Crusius JB, Uitdehaag BM, Garcia Gonzalez MA, Kostense PJ, Polman CH et al. Association of interleukin1 beta and interleukin-1 receptor antagonist genes with disease severity in MS. Neurology 1999; 52(3):595-599.

46 Myhr KM, Raknes G, Nyland H, Vedeler C. Immunoglobulin G Fc-receptor (FcgammaR) IIA and IIIB polymorphisms related to disability in MS. Neurology 1999; 52(9):1771-1776.

47 Evangelou N, Jackson M, Beeson D, Palace J. Association of the APOE epsilon4 allele with disease activity in multiple sclerosis. J Neurol Neurosurg Psychiatry 1999; 67(2):203-205.

48 Acheson ED. Epidemiology of multiple sclerosis. Br Med Bull 1977; 33(1):9-14.

49 Vassallo L, Elian M, Dean G. Multiple sclerosis in southern Europe. II: Prevalence in Malta in 1978. J Epidemiol Community Health 1979; 33(2):111-113.

50 Dean G, Grimaldi G, Kelly R, Karhausen L. Multiple sclerosis in southern Europe. I: Prevalence in Sicily in 1975. J Epidemiol Community Health 1979; 33(2):107-110.

51 Leibowitz U, Kahana E, Alter M. The changing frequency of multiple sclerosis in Israel. Arch Neurol 1973; 29(2):107-110.

52 Alter M, Kahana E, Loewenson R. Migration and risk of multiple sclerosis. Neurology 1978; 28(11):1089-1093.

53 Alter M, Okihiro M, Rowley W, Morris T. Multiple sclerosis among Caucasians and Orientals in Hawaii. Neurology 1970; 20(4):399.

54 Alter M, Leibowitz U, Speer J. Risk of multiple sclerosis related to age at immigration to Israel. Arch Neurol 1966; 15(3):234237.

55 Dean G, Elian M. Age at immigration to England of Asian and Caribbean immigrants and the risk of developing multiple sclerosis. J Neurol Neurosurg Psychiatry 1997; 63(5):565-568.

56 Detels R, Visscher BR, Haile RW, Malmgren RM, Dudley JP, Coulson AH. Multiple sclerosis and age at migration. Am J Epidemiol 1978; 108(5):386-393.

57 Hammond SR, English DR, McLeod JG. The age-range of risk of developing multiple sclerosis: evidence from a migrant population in Australia. Brain 2000; 123 ( Pt 5):968-974.

58 Gale CR, Martyn CN. Migrant studies in multiple sclerosis. Prog Neurobiol 1995; 47(4-5):425-448.

59 Hammond SR, English D, de Wytt C, Maxwell IC, Millingen KS, Stewart-Wynne EG et al. The clinical profile of MS in Australia: a comparison between medium- and high-frequency prevalence zones. Neurology 1988; 38(6):980-986.

60 Alter M, Halpern L, Bornstein B. Multiple Sclerosis in Israel. Arch Neurol 1962; 7:253-263.

61 Kurland L, Reed D. Geographic and climatic aspects of multiple sclerosis: a review of current hypotheses. Am J Public Health 1964; 54:588-597.

62 Larsen JP, Kvaale G, Riise T, Nyland H, Aarli JA. Multiple sclerosis--more than one disease? Acta Neurol Scand 1985; 72(2): 145-150.

63 Weinshenker BG. Progressive forms of MS: classification streamlined or consensus overturned? Lancet 2000; 355(9199):162-163.

64 Lublin FD, Reingold SC. Defining the clinical course of multiple sclerosis: results of an international survey. National Multiple Sclerosis Society (USA) Advisory Committee on Clinical Trials of New Agents in Multiple Sclerosis. Neurology 1996; 46(4):907-911.

65 Kremenchutzky M, Cottrell D, Rice G, Hader W, Baskerville J, Koopman W et al. The natural history of multiple sclerosis: a geographically based study. 7. Progressive-relapsing and relapsing-progressive multiple sclerosis: a re-evaluation. Brain 1999; 122 ( Pt 10):1941-1950.

66 Confavreux C, Aimard G, Devic M. Course and prognosis of multiple sclerosis assessed by the computerized data processing of 349 patients. Brain 1980; 103(2):281-300.

67 Bashir K, Whitaker JN. Clinical and laboratory features of primary progressive and secondary progressive MS. Neurology 1999; 53(4):765-771.

68 McDonnell GV, Hawkins SA. Primary progressive multiple sclerosis: a distinct syndrome? Mult Scler 1996; 2(3):137-141.

69 Weinshenker BG, Bass B, Rice GP, Noseworthy J, Carriere W, Baskerville $\mathrm{J}$ et al. The natural history of multiple sclerosis: a geographically based study. I. Clinical course and disability. Brain 1989; 112 ( Pt 1):133-146.

70 Thompson AJ, Polman CH, Miller DH, McDonald WI, Brochet B, Filippi MM, X et al. Primary progressive multiple sclerosis. Brain 1997; 120 ( Pt 6): 1085-1096.

71 Weiner HL, Mackin GA, Orav EJ, Hafler DA, Dawson DM, Lapierre $\mathrm{Y}$ et al. Intermittent cyclophosphamide pulse therapy in progressive multiple sclerosis: final report of the Northeast 
Cooperative Multiple Sclerosis Treatment Group. Neurology 1993; 43(5):910-918.

72 Goodkin DE, Rudick RA, VanderBrug MS, Daughtry MM, Schwetz KM, Fischer J et al. Low-dose $(7.5 \mathrm{mg})$ oral methotrexate reduces the rate of progression in chronic progressive multiple sclerosis. Ann Neurol 1995; 37(1):30-40.

73 Prat A, Pelletier D, Duquette P, Arnold DL, Antel JP. Heterogeneity of T-lymphocyte function in primary progressive multiple sclerosis: relation to magnetic resonance imaging lesion volume. Ann Neurol 2000; 47(2):234-237.

74 Olerup O, Hillert J, Fredrikson S, Olsson T, Kam-Hansen S, Moller $\mathrm{E}$ et al. Primarily chronic progressive and relapsing/remitting multiple sclerosis: two immunogenetically distinct disease entities. Proc Natl Acad Sci U S A 1989; 86(18):7113-7117.

75 Weinshenker BG, Santrach P, Bissonet AS, McDonnell SK, Schaid D, Moore SB et al. Major histocompatibility complex class II alleles and the course and outcome of MS: a populationbased study. Neurology 1998; 51(3):742-747.

76 Hillert J, Gronning M, Nyland H, Link H, Olerup O. An immunogenetic heterogeneity in multiple sclerosis. J Neurol Neurosurg Psychiatry 1992; 55(10):887-890.

77 Rovaris M, Bozzali M, Santuccio G, Iannucci G, Sormani MP, Colombo B et al. Relative contributions of brain and cervical cord pathology to multiple sclerosis disability: a study with magnetisation transfer ratio histogram analysis. J Neurol Neurosurg Psychiatry 2000; 69(6):723-727.

78 Lucchinetti C, Bruck W, Parisi J, Scheithauer B, Rodriguez M, Lassmann H. A quantitative analysis of oligodendrocytes in multiple sclerosis lesions. A study of 113 cases. Brain 1999; 122
(Pt 12):2279-2295.

79 Riise T, Gronning M, Klauber MR, Barrett-Connor E, Nyland H, Albrektsen G. Clustering of residence of multiple sclerosis patients at age 13 to 20 years in Hordaland, Norway. Am J Epidemiol 1991; 133(9):932-939.

80 Eastman R, Sheridan J, Poskanzer DC. Multiple sclerosis clustering in a small Massachusetts community, with possible common exposure 23 years before onset. N Engl J Med 1973; 289(15):793-794

81 Wikstrom J. Studies on the clustering of multiple sclerosis in Finland. Riv Patol Nerv Ment 1976; 97(4):199-204.

82 Hoffman RE, Zack MM, Davis LE, Burchfiel CM. Increased incidence and prevalence of multiple sclerosis in Los Alamos County, New Mexico. Neurology 1981; 31(11):1489-1492.

83 MacGregor HS. Multiple sclerosis clusters in Florida. J Epidemiol Community Health 1991; 45(1):88.

84 Hader WJ, Irvine DG, Schiefer HB. A cluster-focus of multiple sclerosis at Henribourg, Saskatchewan. Can J Neurol Sci 1990; 17(4):391-394

85 Armon C, Daube JR, O'Brien PC, Kurland LT, Mulder DW. When is an apparent excess of neurologic cases epidemiologically significant? Neurology 1991; 41(11):17131718.

86 Riise T. Cluster studies in multiple sclerosis. Neurology 1997; 49(2 Suppl 2):S27-S32.

87 Granieri E, Casetta I, Tola MR, Govoni V, Paolino E, Malagu S et al. Multiple sclerosis: does epidemiology contribute to providing etiological clues? J Neurol Sci 1993; 115 Suppl:S16S23.

Scott Sloka is to be the first year Neurology resident at Memorial University of Newfoundland this summer. He holds a BASc in Electrical Engineering and a $\mathrm{PhD}$ in Image Processing from the University of Waterloo. His research interests include image understanding and pattern recognition, autoimmunity, and neuroepidemiology. 